\title{
The Utilization of Abandoned Petroleum Wells in Geothermal Energy Sector. Worldwide Trends and Experience
}

\author{
Anna Chmielowska ${ }^{1, *}$, Barbara Tomaszewska ${ }^{1}$, and Anna Sowiżdżał ${ }^{1}$ \\ ${ }^{1}$ AGH University of Science and Technology, Faculty of Geology, Geophysics and Environmental \\ Protection, Department of Fossil Fuels, Mickiewicza 30 Av, 30-059 Kraków, Poland
}

\begin{abstract}
Since the oil crises in the 1970s, geothermal resources have received much attention and researches aimed at its recognition have been conducted all around the globe. Nevertheless, the investment cost associated mainly with drilling works is a crucial limitation for the successful implementation of new geothermal projects. The radical solution affecting the cost effectiveness of any geothermal investments might be an adaptation of existing un-exploited boreholes of the oil and gas sector for geothermal purposes. Moreover, a few studies on heat and/or energy recovery from oil and gas provinces have indicated that a tremendous amount of geothermal energy co-exists with petroleum fields. Thereby, the article centres on global concepts related to the adaptation of boreholes after the exploitation of hydrocarbon deposits or negative exploratory wells in order to exploit geothermal energy resources. Selected concepts focused on possible electricity production and the space heating sector are discussed. Other potential technologies based on utilization of geothermal energy attained by borehole heat exchangers are also indicated.
\end{abstract}

\section{Introduction}

Geothermal energy is considered to be a strategic, sustainable and environment-friendly source of renewable energy, all around the globe. It can be effectively managed in several economic sectors, contributing to the increase of an energy efficiency and improving living conditions of citizens [1]. Depending on the temperature of the geothermal medium, it is used in the broadly defined district heating sector, recreation and balneotherapy, agriculture, industry [2] and electricity generation [3]. Being the natural internal heat of the Earth, geothermal energy constitutes a viable alternative to conventional resources that are the basis of modern world economies [4]. Nonetheless, their exploitation is associated with an adherence to the formal and legal regulations, and often constitutes a heavy financial burden of a potential investment. What is more, accessing geothermal energy resources of relevant parameters (temperature, pressure, outflow, etc.) is possible only due to the deep boreholes, which at the current stage of technological development are the only rational

\footnotetext{
*Corresponding author: adrabik@agh.edu.pl
} 
solutions. Nevertheless, a drilling stage is the largest financial burden of any geothermal investment - on average up to $70 \%$ of the total investment costs, often making them economically unprofitable [5]. This prompts the world to look for other solutions that will enable efficient and economically justified acquisition of geothermal energy.

Every year, due to the depletion of oil and gas resources, more and more boreholes are being abandoned and/or liquidated. So far, the number of abandoned oil and gas wells, all over the world, reaches even 30 million $[5,6]$. In addition, many of them are located in areas characterized by favorable geothermal parameters, which often translates into significant geothermal potential. The possibility of transforming those petroleum wells into geothermal ones may result in not only limiting investment costs related to the omitting the drilling stage $[5,7]$, or increasing the use of geothermal resources, but also reducing the threat to the natural environment [8]. Therefore, the re-development of old petroleum boreholes for the purpose of acquiring geothermal energy is an extremely desirable solution and simultaneously the outstanding subject of significant number of researches around the globe. Scientists have considered various concepts for obtaining both thermal energy [7, 9, 10] and electricity production [4, 11, 12], depending on specific regional thermal conditions.

It is also important to pay attention to the term of abandoned oil and gas wells that is commonly used in the international literature. In fact, it refers both to the boreholes liquidated due to the depletion of oil and gas resources as well as to old negative exploratory wells $[4,5,9]$. Thus, this paper focuses on issues related to the development of these boreholes for different geothermal applications considering most notably the idea of implementation of borehole heat exchangers (BHEs). The concept of adaptation of old petroleum wells for geothermal purposes in closed-loop systems for heat and electricity production is widely discussed.

\section{Borehole Heat Exchanger}

Although the tremendous amount of geothermal energy co-exists with petroleum fields, the temperatures of these regions are not always high enough for a direct utilization. Hence, the currently conducted researches on the assessment of the possibility of using existing oil and gas wells to obtain geothermal energy are mostly directed at the implementation of borehole heat exchanger technology [13]. The borehole heat exchanger (BHE) is a device used to extract heat from shallow and/or deep rock formations without any geofluid production. Technically, it is a heat exchanger installed inside the selected borehole, circulating any heat-carrying fluid (predominantly water) through it [14]. The vertical heat exchanger can be made in one of two basic types: coaxial pipes or in the form of U-tube (Fig. 1). The borehole round the pipes is backfilled with a material characterized by a high thermal conductivity. The injected water collects heat from the surrounding rock formations, warms up and then returns to the surface - the circulation of the medium is schematically presented in the Figure 1. Generally, the deeper the BHE is, the heat transfer area is larger, the temperature of the surrounding rock, as well as the heat conductivity is higher. Thus, higher output temperature can be attained by the so-called deep borehole heat exchangers (DBHEs), which are transformed from dry unsuccessful or existing unexploited hydrocarbon wells [14]. 

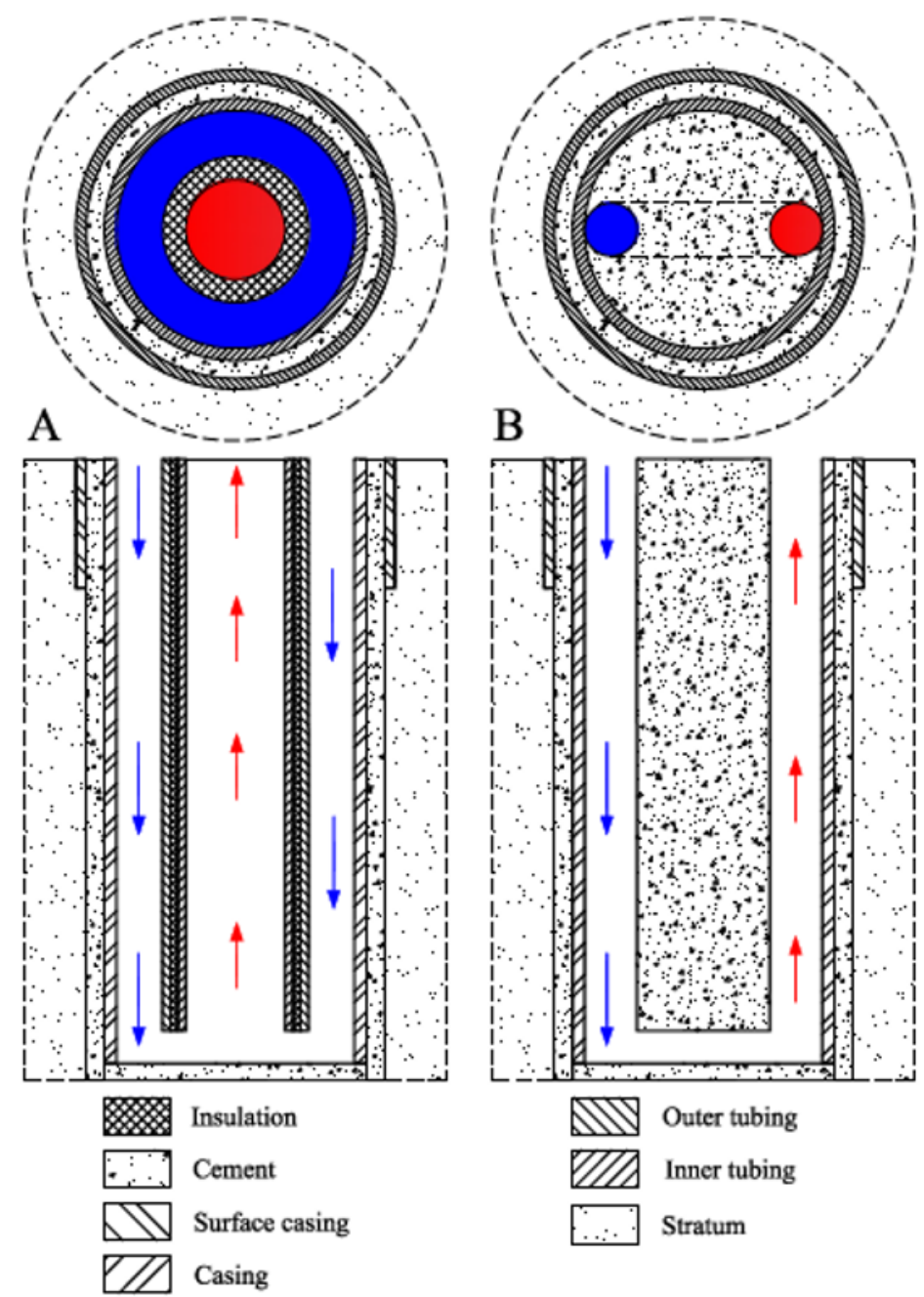

MIV Outer tubing

DD Inner tubing

Stratum

Fig. 1. Borehole heat exchanger: A - coaxial, B - U-pipe; based on [6, 12].

\section{Re-adaptation of Petroleum Wells}

As world experience shows, there is the possibility of effective adaptation of petroleum boreholes or negative exploratory wells in the geothermal energy sector $[9,15]$. The vast majority of them make use of the classic geothermal system, while the issues of efficiency of DBHEs are constantly analyzed. According to Templeton et al. [9], there is only one study in which a numerical model describing the efficiency of a U-tube BHE (Fig. 1B) operating in an old petroleum well was discussed. On the other hand, the subject of coaxial BHEs (Fig. 1A) working on old exploitation wells is much more popular among the scientific society and it was dealt with by among others: Davis and Michaelides [11], Bu et al. [7] or Cheng et al. [4, 16, 17]. The main purposes of using this technology are primarily the ability to produce electricity, possible use in heating sector or other technological applications, such as e.g. heat storage. 


\subsection{Production of Electricity and Heating Sector}

The concept of adaptation of wells after exploitation of hydrocarbons to obtain geothermal energy (for heating purposes) is based mainly on the use of a coaxial BHEs (Fig. 1A). Templeton et al. [9] focused primarily on the development of a heat exchange model occurring between the BHE and the surrounding rock formation. They based their considerations on the real values of parameters regarding the rocks and the borehole, referring them to the Persian Gulf area. In turn, Nian and Cheng [10] evaluated the possibility of heating a virtual building with the area of $10,000 \mathrm{~m}^{2}$, considering the existing petroleum well located within the Shengli oil field in China (depth 3,000m, gradient $33^{\circ} \mathrm{C} / \mathrm{km}$ ) as a coaxial DBHE (Fig. 1A). In their research, they proved that the presented concept can be effectively used both for heating a building and for supporting an existing source of heat, under given geothermal conditions [10]. At the same time, the authors emphasized the ecological and economic importance of the analyzed investment. Bu et al. [7] focused mainly on the production of electricity using a $4,000 \mathrm{~m}$ deep oil\&gas well (gradient $25-45^{\circ} \mathrm{C} / \mathrm{km}$ ). Nevertheless, in their work they also stated that it is theoretically possible to use accumulated energy in a cascade system (apart from electricity production). The used water was characterized by a high temperature (around $60^{\circ} \mathrm{C}$ ) allowing its use for complex heating purposes [7].

The re-use of petroleum boreholes for electricity generation was presented, among others, by Davis and Michaelides [11]. In order to conduct the analysis, the authors selected the borehole in Texas (the United States) with a depth of $3,000 \mathrm{~m}$ and a temperature at the bottom of the hole equal to $140{ }^{\circ} \mathrm{C}$. Like their predecessors, they presented a concept based on a coaxial DBHE (Fig. 1A). Isobutene was used as a working medium, and electricity production was held in a binary system based on the Organic Rankine Cycle (ORC) (Fig. 2 ). The authors focused primarily on the variable parameters: downhole temperature and geothermal gradient, as well as the depth of the hole and the optimization of the diameter of the internal channel. They proved that the obtained power (on average $2-3 \mathrm{MW}$ ) depends mainly on the temperature at the bottom of the hole, the pressure and injection speed, and the geometric characteristics of the heat exchanger (diameter and thickness of thermal insulation). As a result of the modeling, the authors obtained a maximum result of 3.4 MW of electric power for an average petroleum borehole located in the southern Texas, indicating temperature conditions at $177^{\circ} \mathrm{C}$ and injection pressure of 30 bar as sufficient and optimal [11].

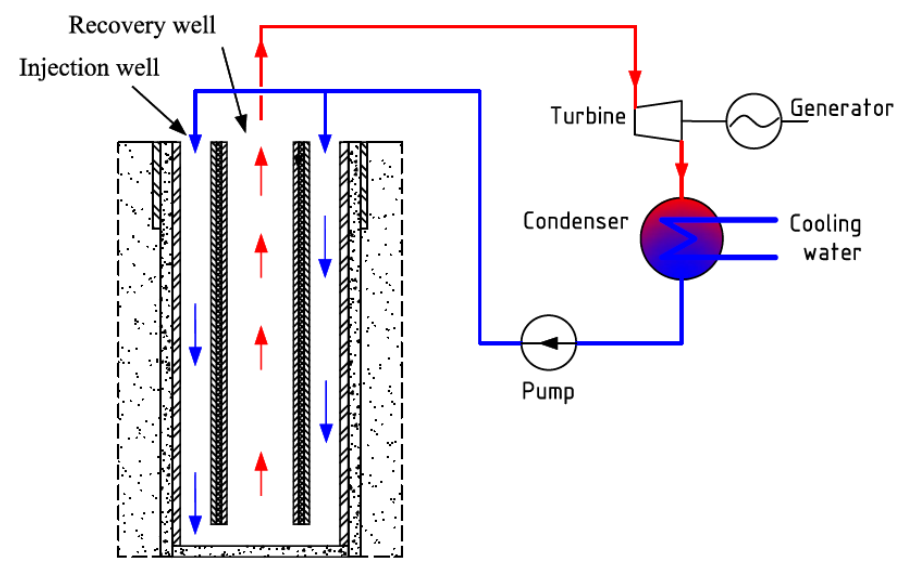

Fig. 2. Simplified diagram of geothermal power generation with coaxial DBHE and organic Rankine cycle ORC; based on [11]. 
These aforementioned works have become the inspiration and at the same time the basis for conducting further research on the possibility of using concentric DBHEs as a technology for the re-use of abandoned petroleum and/or negative exploratory wells [10]. $\mathrm{Bu}$ et al. [7] compared the amount of electricity production and collected thermal energy to the selection of a suitable volumetric flow of heat-carrying fluid, under the specific hydrogeothermal parameters (mainly gradient values). In addition, they proved that the adaptation of wells after hydrocarbon exploitation could reduce the investment costs of a geothermal project even by $50 \%$, rendering any potential project more profitable [7]. In turn, Ghoreishi-Madiseh et al. [18] developed a three-dimensional model of a heat exchange between the rock formation and the DBHE, showing, among other things, the importance of (previously neglected) natural (or forced) filtration of groundwater. On the other hand, scientists from China presented an innovative calculation model for a heat exchange [4]. They also focused on analyzing the impact of a seven given type of organic heat-carrying fluid on the heat transfer process and consequently on the production of electricity [16]. Then, Ebrahimi and Torshizi [19] referred their research to the great significance of the scale of transformations launching a boreholes' network. They suggest that the use of at least two wells makes the system more reliable and can bring tangible economic benefits.

\subsection{Other Possible Applications}

So far, scientists have focused mainly on the use of old boreholes adapted for DBHEs in order to obtain thermal energy and also for the possible production of electricity. Nevertheless, the interest in the issue of the use of petroleum holes has prompted scientists to look for other useful applications. One of the more interesting ones is the assessment of the possibility of solar energy storage using the concentric borehole heat exchanger presented by Templeton et al. [20], or the implementation of the desalination system of sea water presented by Noorollahi et al. [21, 22]. Also, considering the open-loop systems, a novel approach is the attempt to combine the re-adaptation of boreholes after the exploitation of hydrocarbons for a DBHE with the technology of Enhanced Geothermal Systems (EGS), which is discussed by Cheng et al. [17] as well as Caulk and Tomac [5].

\section{Conclusion}

Geothermal energy is a renewable source of energy endowed with considerable energetic potential due to the low impact on the natural environment and its ability to be extracted from fairly all over the globe. The use of petroleum wells (research, exploratory or exploitative) is one of the main directions of the development of the global geothermal energy sector. The conducted research is focused on the development of technology enabling efficient and economically profitable acquisition of electricity and heat, in a manner consistent with strict environmental requirements and being a part of the energy policy. As evidenced by numerous studies, the re-adaptation of abandoned petroleum and/or negative exploratory wells not only limits their negative impact on the natural environment, but also increases the economic viability of the geothermal project, reducing investment costs even by up to $50 \%$. The particularly considered issue is to increase the efficiency of using deep coaxial borehole heat exchangers (DBHEs) for heat generation and production of electricity. Nevertheless, scientists have been successfully working on possibility for cascade use of gained energy (mainly thermal) as well as on ideas for other technological applications, e.g. storage of energy, desalination of sea water, etc. 
Summing up, the conducted research shows that the use of boreholes liquidated due to the depletion of oil and gas resources and/or dry unsuccessful wells is possible in areas characterized by a favorable geothermal potential (geothermal gradient, heat flux) and in many cases it is economically justified. Summarily, it is highly recommended to adapt old existing boreholes for any efficient geothermal applications, especially in a cascade mode.

The paper has been prepared under the AGH-UST statutory research grant No. 11.11.140.031 and grant No. 15.11.140.189.

\section{References}

1. A. Sowiżdżał, A. Chmielowska, B. Tomaszewska, A. Operacz, J. Chowaniec, Arch. Environ. Prot. 3 (2019)

2. J.W. Lund, T.L. Boyd, Geothermics 60 (2016)

3. R. Bertani, Geothermics 60 (2016)

4. W.L. Cheng, T.T. Li, Y.L. Nian, C.L. Wang, Energy 59 (2013)

5. R.A. Caulk, I. Tomac, Renew.e Energ. 112 (2017).

6. Y.L. Nian, W.L., Renew. Sust. Energ. Rev. 87 (2018)

7. X. Bu, W. Ma, H. Li, Renew. Energ. 41 (2012)

8. R.J. Thiessen, G. Achari, Toxicol. Environ. Chem. 99 (2016)

9. J.D. Templeton, S.A. Ghoreishi-Madiseh, F. Hassani, M.J. Al-Khawaja, Energy 70 (2014).

10. Y.L. Nian, W.L. Cheng, Energy 142 (2018)

11. A.P. Davis, E.E. Michaelides, Energy 34 (2009)

12. N.M. Wight, N.S. Bennett, Applied Thermal Engineering 89 (2015)

13. A. Sapińska-Śliwa, M.A. Rosen, A. Gonet, T. Śliwa. Proceedings World Geothermal Congress 2015 Melbourne, Australia, 19-25 April 2015

14. A. Toth, E. Bobok, Chapter 13 Borehole Heat Exchangers. Flow and Heat Transfer in Geothermal Systems (2017)

15. A. Chmielowska, B. Tomaszewska, A. Sowiżdżał, Web of Science (2019)

16. W.L. Cheng, T.T. Li, Y.L. Nian, K. Xie, Appl. Energ. 118 (2014)

17. W.L. Cheng, J. Liu, Y.L. Nian, C.L. Wang, Energy 109 (2016)

18. S.A. Ghoreishi-Madiseh, F.P. Hassani, M.J. Al-Khawaja, Proceedings of the world renewable energy forum, WREF (2012)

19. M. Ebrahimi, S.E.M. Torshizi, J. Renew. Sustain. Ener. 4 (2012)

20. J.D. Templeton, F. Hassani, S.A. Ghoreishi-Madiseh, Renewable Energy 86 (2016)

21. Y. Noorollahi, M. Pourarshad, S. Jalilinasrabady, H. Yousefi, Geothermics 55 (2015)

22. Y. Noorollahi, S. Taghipoor,B. Sajadi, Geothermics 67 (2017) 